significa libertad de cualquier relación con los demás salvo aquellas relaciones en las que el individuo entra voluntariamente por su proplo interess.

III) El individuo es esencialmente el propietario de su propia persona y de sus capacidades. por las cuales nada debe a la sociedad.

[...]

IV) Aunque el individuo no puede alienar toda su propiedad sobre su propia persona, puede alienar su capacidad para trabajar.

v) La sociedad humana consiste en una serie de relaciones mercantiles.

[...]

VI) Dado que lo que hace humano a un hombre es la libertad de las voluntades ajenas, la libertad de cada individuo solamente puede limitarse justamente por unas obligaciones y reglas tales que sean necesarias para garantizar la misma libertad a los demás.

VII) La sociedad polftica es una invención bumana para la protección de la propiedad que el individuo tiene sobre su propia persona y sobre sus bierses, y (por tanto) para el mantenimiento de relaciones de cambio debidamente ordenadas entre individuos considerados como propietarios.*

8. M. Bakunin, op, cit., p. 10 .

9. Ibid., p. 17.

10. E. Malatesta, «El individualismo en el anarquismon, en Socialismo y anarquia, op. cit., p. 58 .

11. M. Bakunin, op. cit. p. 18.

12. E. Malatesta, La anargufa, Bilbao, Zero, 1978, p. 50 .
13. J. Locke, op. cit., cap. $9, \mathbf{n}_{*}$ " 124.

14. E. Malatesta, La anarquia, op, cit., p. 76 .

15. Mbid, p. 76.

16. R. Nozick, Anarguía, Estado y utopia, Mexico, Fondo de Cultura Económica, 1988.

El autor, a lo largo de toda la obra, intenta convencemos de la necesidad, justicia y posibilidad de lo que él denomina astado mfnimon e incluso *ultrammimos que, en definitiva, no es otra cosa que el estado liberal, subsidiario de la sociedad civil en lo que los individuos y sus asociaciones elementales no pueden lograr por st mismos. Ese sestado mfnimos, por otra parte, pretende autonomizarlo de los restantes niveles sociales, en concreto del economico, en unos planteamientos tan absolutamente ingenuos que sorprende verlos reflejados en una obra que se pretende enjundiosa y que ha levantado ura gran expectacion. Transcribo un fragmento a modo de ilustracion: aAunque la estructura es libertaria y de laissez-faire, las conunidades individuales dentro de ella no necesitan ser ast $\mathrm{y}$, tal vez ninguna comunidad dentro de ella escoja ser asi. De esta manera, las características del marco no necesitan introducirse en las comunidades individuales. En este sistema de laissez-faire podria resultar que, aunque están permitidas, no hay instituciones "capitalistas" realmente funcionando; o bien, que algunas comunidades las tienen $y$ otras no o que algunas comunidades tienen algunas de ellas, o lo que usted quiera (p. 308).

17. P. Kropotkin, entrada anarqua de la edición de 1905 de la Enciclopedia Británica, en Obras, Barcelona, Anagrama, pp. 38-39.

18. Ibid, p. 39.

\title{
Las libertades inseparables, o razones y dudas del neoliberalismo
}

\author{
PEDRO SCHWARTZ \\ Universidad Autónoma de Madrid
}

Durante una breve época, que casi coincide con la década de 1980 , parecio a algunas mentes superficiales y supersticiosas que el ideario basado en la conjunción de las libertades personales, políticas, sociales y econórmicas, ideario que podríamos llamar "liberalismo ortodoxo", o «liberalismo de mercado", iba a triunfar necesaria y definitivamente. Incluso aparecio un escritor hegeliano, Francis Fukuyama, que se hizo famoso anunciando el final de 
la historia, por la inevitable victoria del capitalismo avanzado unido a la democracia política.

Curiosamente, las dudas y la vuelta atrás han comenzado justo en el momento en que la democracia capitalista consiguió su mayor triunfo: el año de 1989, el año de la caída del Muro de Berlín, el año que cierra un siglo de democracia totalitaria iniciada en la Revolución Francesa. No sólo hablo de la espuma de las modas ideológicas, como la que siguen quienes denuestan el capitalismo desde las pantallas de cine y televisión, y desde las páginas de novelas y periódicos, como el imperio del dinero fácil y sin escrúpulos. Hablo también de los intentos de la izquierda desorientada de reorganizarse en nombre de una ética de la solidaridad; o de Ios esfuerzos de una derecha desarraigada de reagruparse en nombre del nacionalismo.

El búho de Minerva ha de levantar el vuelo en el crepúsculo de los dioses tribales. Importa mucho, en $\mathrm{mi}$ opinión, que los liberales no se adormezcan con los efluvios del incensario y analicen por qué están equivocados quienes postulan una inevitable y definitiva victoria del capitalismo liberal. También es esencial tomar en serio a quienes rechazan la democracia capitalista en nombre de una ética humanista, o la temen por su carácter disolvente de la sociedad tradicional. La libertad siempre está en peligro: los que la creen inevitable bajan la guardia; los que la creen inhumana buscan dividirla o detenerla.

Hay que ponerse a pensar. Los liberales españoles tenemos que analizar al menos los peligros que corren las libertades en España y a cxorcizar los demonios familiares de nuestra tribu española. Algunos de los íncubos parecen dormir, como el de la intolerancia religiosa; otros apuntan, como el de la corrupción caciquil o la expulsion xenofoba; alguno se disfraza de beneficente Estado providencia; y los hay que nunca han dejado de campear, como el espíritu gremial del estanco.

\section{Inestabilidad de elementos}

Comenzare por indicar, si se me permite utilizar una metáfora matemática, qué argumentos componen el polinomio del liberalismo ortodoxo.

El liberalismo, para mí, al conceder un valor fundamental al individuo, fia el optimo funcionamiento de las sociedades humanas en la máxima posible libertad social y económica. Según la interpretación clásica de esta doctrina política, la libertad individual sólo está garantizada cuando se cumplen cinco condiciones: cuando se respetan los derechos humanos, se reconoce la igualdad de las personas ante la ley, se establece la división de los poderes del Estado, se defienden la propiedad privada y el cumplimiento de los contratos, y se franquea la concurrencia económica.

Dicho de otra forma, la sociedad liberal es la sociedad del acuerdo voluntario. En este sentido cabe entender la alianza, a veces incómoda, entre liberalismo y democracia. En la medida en que el liberalismo busca en la mayor medida posible dar a los individuos y a las minorías un veto sobre las decisiones sociales que atentan contra su individualidad o su propiedad, en esa medida el liberalismo es afín al principio de limitar las decisiones colectivas a lo que se acucrde unánimemente o por mayorías lo más amplias posibles. El principio del liberalismo es compatible con el principio democrático en la medida en la que ambos buscan minimizar la coacción y la violencia - a veces, inevitablemente con el uso de la fuerza legalmente constituida. Aquí 
aparece la primera antinomia del liberalismo: necesita de un modicum de fuerza para ser estable. Existirá siempre una tensión entre la libertad individual y el marco coactivo: esta tensión se resuelve en parte por la obligación espontáneamente asumida por los individuos de cumplir la ley, pero exige también la existencia de una institución coactiva para disciplinar los tramposos. El Estado es indispensable para la supervivencia de la sociedad liberal, para el mantenimiento de los derechos de propiedad y el cumplimiento de los contratos, pero tiene en sí un principio de monopolio de la coacción que es contrario a la libertad. Por un lado pone en peligro los derechos humanos. ¿Cómo domesticar al Leviathan? Por otro es un peligro para la propiedad privada, porque se apoderen de él quienes quieren expropiar en su propio beneficio la riqueza legitimamente adquirida de los demás. ¿Cómo impedir que se convierta en un ogro filantrópico?

Otro elemento de inestabilidad es el que nace de la contradicción entre la defensa de la propiedad privada y el respeto de la libre formación de los precios: Para el propietario de un activo o poseedor de una capacitación, la caída de un precio puede significar una pérdida de capital semejante a la sufrida tras un robo. Los bajos precios del petróleo empobrecen a los dueños de los pozos kuwaitíes casi tanto como si hubiesen sido expoliados por los iraquies. En general, el tiempo, el librecambio, y la tendencia genética hacia la media hace que los valores establecidos y las rentas y derechos adquiridos pierdan valor: así, los campesinos franceses se resisten al laissez-faire porque disminuye la distancia que les separa de agricultores más pobres. En el capitalismo hay una perpetua tendencia a formar monopolios, y sobre todo a conseguir monopolios legales para combatir la igualdad económica traída por la libre competencia. «La gente del mismo negocio rara vez se reúne, aunque sea para divertirse, sin que su conversación acabe en una conspiración contra el público o en alguna triquiñuela para elevar los precios», denunció Adam Smith.

Un último y más profundo elemento de inestabilidad fluye de la primacía del individuo en el capitalismo democrático. La sociedad capitalista es una comunidad que satisface muy escasamente los instintos gregarios y tribales del homo sapiens. Como dice Hayek en su magistral epílogo a Derecho, legislacion y libertad, "Las tres fuentes de la valoración humana", "la moralidad que mantiene la sociedad abierta no sirve para gratificar las emociones humanas".

\section{Confusión de conceptos}

El liberalismo, en palabras de John Locke, supone que los individuos atienen un derecho natural a la vida, a la libertad, y al goce de sus propiedades». La claridad de estos principios básicos de partida no ha impedido que las diversas maneras de entender el liberalismo a lo largo de la historia hayan llegado a hacer de él un término ambiguo.

Debido a la falta de juicio en la solución de las antinomias que acabo de reseñar, ha habido liberales próximos al anarquismo; y otros tentados por un igualitarismo cuasi-socialista. Ha habido gentes tan amantes del orden establecido, que hubieran impedido siquiera que se obligara a los dueños de esclavos a que tuviesen que liberarlos a cambio de una indemnización (como ocurrió en las Antillas británicas); y otros tan enamorados de la eficiencia social que son capaces de defender la 
expropiacion forzosa de propiedades sin alma. Y por horror al vacío de la sociedad abierta, ha habido liberales nacionalistas ( $y$ no sólo en la Alemania fichteana o la Italia garibaldina), frente a liberales partidarios del esperanto y del gobierno mundial.

La confusión de los conceptos es un mal que aqueja especialmente la doctrina liberal. Se confunde liberalismo con anarquismo. El anarquismo olvida el mito que relata cómo la pareja humana fue expulsada del paraiso terrenal por haber comido el fruto del árbol del bien y del mal. Si la organización estatal ha proliferado y tantas comunidades luchan por constituirse en Estado, alguna virtud debe de tener, pese a los abusos que los liberales combaten. Los liberales no han buscado la atrofia del Estado, sino un Estado fuerte y pequeño. En palabras de Adam Smith, "en el sistema de la libertad natural, [...] el soberano tiene que atender a tres deberes: [...] primero, el deber de proteger la sociedad de la violencia e invasión de otras sociedades independientes; segundo, [...] el de establecer una exacta administración de justicia; tercero, el de erigir y mantener ciertas obras públicas y ciertas instituciones [...] que no interesa a ningún individuo en particular, [...] pero que más que compensa a una gran sociedad,.

Se confunde, y sobre todo se confundió en el s. xIx, liberalismo y nacionalismo. El nacionalismo se preocupa de unificar el pueblo titular de la soberanía sobre bases cuasi-tribales y no tiene escrúpulo en utilizar para ello nociones como la religión, el idioma o la raza. Mientras que el liberalismo busca la combinación del cosmopolitismo implícito en la libre circulación de los bienes, servicios, capital y personas, y del espontáneo sentimiento patriota por la tierra en que uno nació o se alincó.
Se confunde liberalismo y socialismo. Me cansa oír a quienes repiten la frase hecha de que son "socialistas a fuer de liberales». El socialismo no se contenta con defender la igualdad de las personas ante la ley, sino que busca la igualdad de oportunidades e incluso la igualdad de resultados, sin detenerse ante el carácter coactivo de la intervención en favor do quienes considera desfavorecidos.

En los Estados Unidos de América, "liberalismon se emplea hoy como sinónimo de intervencionismo social-demócrata. La frase de la Declaración de Independencia de 1776: "Sostenemos que estas verdades son evidentes: que todos los hombres son creados iguales, que están investidos por su Creador de ciertos derechos inalienables, que entre estos Derechos se encuentran Ia Vida, la Libertad, y la Búsqueda de la Felicidad [...] y contiene una inoportuna modificación de la acertada fórmula de Locke: ala Vida, la Libertad, y el Disfrute de su Propiedad". Si bien el cambio lo realizó hábilmente Jefferson para que los anti-esclavistas entre los colonos del norte, en especial los cuáqueros, pudiesen firmar dicha Declaración, quedó así abierto el portillo a la idea de que la felicidad es un derecho de los hombres. De aquí que en America se haya acogido con entusiasmo entre los más sentimentales la discutible idea de que las libertades, tradicionalmente concebidas como barreras frente a la violencia o la coacción, quedan vacías de significado si no se otorgan a todos los individuos todos los medios para gozar de la felicidad, sin necesidad de que los conquisten. Así adquírí en los EE.UU. la palabra "liberal» el carácter intervencionista y socializante que hoy tiene, mientras que la expresión «conservador" significa a menudo un defensor del espíritu individualista evidenciado por los padres 
de la Constitución americana de 1787 , es decir, un liberal ortodoxo en sentido europeo. Por suerte, la Cato Foundation ha acuñado una nueva expresión que salva para los EE.UU. el contenido de este ideario, mezcla de soberanía del individuo sobre su vida personal (lo que choca con el puritanismo de algunos conservadores) y de la plena libertad de empresa (lo que disgusta a los socializantes): market liberal, liberal del mercado.

Se confunde, como he insinuado mas arriba, democracia y liberalismo. Pero, como dijo Ortega, «Democracia y liberalismo son dos respuestas a dos cuestiones de Derecho político totalmente distintas. La democracia responde a esta pregunta: ¿Quién debe ejercer el Poder Público? [...] El liberalismo en cambio responde a esta otra pregunta: ejerza quienquiera el Poder público, ¿cuáles deben ser los límites de éste? La respuesta suena asi: el Poder no puede ser absoluto, ejérzalo un autócrata o el pueblo, sino que las personas tienen derechos propios a toda injerencia del Estadon.

\section{Historia de la génesis del liberalismo}

El desarrollo del liberalismo en el mundo occidental y sobre todo en España es una de las mejores maneras de ver que, pese a tales contradicciones, es un ideario que ha sabido recoger más cabalmente que los idearios anarquista, nacionalista y socialista, con los que a menudo ha estado aliado, los elementos de tolerancia ideológica, de excelencia individual, $y$ de creencia en valores objetivos, que caracterizan lo mejor de la civilización occidental. Me atrevo a pensar que en cuestiones de filosofia política, la Historia es maestra de la Vida.

Aunque se le tiene como filosofía contemporánea, el liberalismo comen- zó a florecer en el s. Xvi y lo hizo sobre la base del individualismo filosófico, a su vez producto de una larga evolución histórica. Los primeros brotes de ese individualismo aparecieron en las ciudades democráticas de la Helade antigua, especialmente, por cuanto se refiere a la libertad intelectual y políti$\mathrm{ca}$, en la Atenas de Pericles. Otro elemento importante de la filosofía individualista, la creencia en la dignidad e igualdad fundamentales de todos los hombres y mujeres, libres o esclavos, estaba implícito en la enseñanza de las religiones cristianas. Esos inicios de libertades políticas e intelectuales y ese reconocimiento de la igualdad de derechos humanos tardaron un milenio y medio en dar fruto, desplazados por contrarios impulsos jerarquizadores e inquisitoriales. Tampoco eran individualistas, sino más bien estamentales, los derechos políticos y procesales concedidos en los fueros de la Edad Media, el más célebre de los cuales es la Magna Charta, otorgada a la fuerza por el rey Juan sin Tierra a sus barones a la vera del Támesis en el año de 1215 . si exceptuamos la institución del interdicto de habeas corpus, verdadero obstáculo a la detención arbitraria. Tales fueros y privilegios contribuyeron en determinados países occidentales, desde Inglaterra hasta Navarra y Catalufia, pasando por Flandes o los cantones helvéticos, a crear las costumbres que hicieron de la libertad una tradición europea.

Otros elementos del individualismo fueron acumulándose en Europa occidental a partir del siglo xIV. La independencia burguesa comenzó a florecer en las ciudades mercantiles del norte de Italia y de la desembocadura del Rhin. En esas mismas ciudades nació el humanismo renacentista, que contribuyó a apartar la atención de lo trascendente para fijarla en la plenitud 
del hombre en esta Tierra. Esencial también resultó la reivindicación por Lutero del libre examen de las Sagradas Escrituras, con que se inició la reforma protestante. Esa libre interpretación de los Libros Santos se secularizo durante la revolución puritana en Inglaterra, hasta convertirse en una reivindicación de la libertad de opinión e imprenta, simbolizada por el folleto de John Milton titulado Areopagitica (1644); para luego encarnarse en Ia ciencia experimental moderna. Finalmente, los derechos naturales del hombre, promulgados por los doctores escolásticos a través de los siglos, se secularizaron en la obra de Locke y de los ilustrados franceses, y se universalizaron con la formulación del individualismo ético de Manuel Kant, resumido en el imperativo categórico que insta a "no usar nunca a los individuos solamente como un instrumento".

Sobre estos elementos individualistas comenzo a construirse el liberalismo político. La primera revolución moderna no fue quizá la de las Comunidades de Castilla, pero sí la que culmino con el ajusticiamiento del rey de Inglaterra Carlos I en el patio de Whitehall en 1649. La Cámara de los Comunes, o más bien lo que había quedado de ella tras repetidas purgas $y$ una guerra civil, doblegó así, en nombre de los representantes del pueblo religioso, el poder divino del Rey. Restaurados los Estuardos, una segunda revolución, la de 1688 contra Jacobo II, hizo culminar la reinterpretación moderna de la teoría de las Cortes medievales que, de ser vistas como la representación estamental basada en privilegios y fueros, comenzaron a entenderse en un sentido más actual como la expresión de una soberanía compartida.

Los efectos de todas estas convulsiones políticas parccieron quedar en sus- penso en el Continente europeo durante un siglo entero, en el que el poder de los reyes absolutos se impuso sobre los movimientos populares o liberadores. La hibernación del liberalismo no era sino apariencia, pues el siglo Xvm fue el siglo de la construcción del Estado, una institución que, paradojicamente, resulto ser de importancia capitál en la sociedad liberal de los siglos posteriores. Al propio tiempo, la filosofra liberal, especialmente en la obra de Montesquieu, insistió en una salvaguardia que se pensaba tomada de la Constitución inglesa: la separacion de los poderes.

Precisamente en aquellos años finales del siglo xvur la doctrina liberal completaba su estructura al añadir el liberalismo económico al pensamiento constitucional. En Francia, los economistas Quesnay y Turgot acuñaron la frase "laissez faire, laissez passern; y David Hume y Adam Smith en Escocia descubrieron la mano invisible, que lleva a los individuos a contribuir insensiblemente al bien común cuando buscan únicamente su propio interés.

Mucho de ello confluyó en el primer texto constitucional del individualismo liberal, la Carta de los derechos del hombre y del ciudadano, promulgada en 1789 por la Asamblea Nacional francesa. Pero los propios revolucionarios franceses pronto conculcarán tales derechos personales y políticos, en aras de una interpretación totalitaria y nacionalista de los mismos, por no entenderse en la tradición racionalista, geométrica del liberalismo a la francesa, el origen feudal y consuetudinatio de las libertades. Como dice Ortega, los derechos del hombre "son franquías medievales y nada más».

En España prendió de tal suerte la idea de la libertad individual entre unas minorías preparadas para ella gracias a muchos años de Ilustración, 
que la voz "liberal" se difundió como vocablo de origen español. Dice Pedro Grases en un comentario que se ha hecho famoso, que «la voz liberal fue usada con su nuevo significado político en las Cortes de Cádiz, 1809-1813, durante la época de las luchas antinapoleónicas, en oposición a los serviles, mote con que se denominaron los acomodaticios y partidarios de la situación creada por el poder bonapartistay.

La historia del siglo $\mathrm{XX}$ español podría caracterizarse como una larga y victoriosa lucha civil del liberalismo sobre las otras ideologías políticas, hasta conseguir que, durante unos breves años reinaran en nuestro país inusitadas libertades políticas y económicas. Vuelto el siglo, los elementos contradictorios del liberalismo comenzaron a separarse hasta permitir la disolución del sistema bajo los embates del socialismo y del nacionalismo.

En el campo político, la búsqueda de un sisterna liberal equilibrado no culmino hasta la Restauración de la monarquía constitucional en la persona de Alfonso XII. En los años que median entre la Constitución de 1812 y esa de 1876, los liberales por un lado hubieron de enfrentarse con los absolutistas, luego transformados en carlistas; y por otro se enzarzaron en luchas intestinas, y a menudo cruentas, entre moderados y progresistas.

Nuevamente en el trono Fernando VII, la Constitución de Cádiz fue abolida hasta la rebelión liberal de Riego en Cabezas de San Juan en 1820, a la cabeza del ejercito destinado a combatir el renovado movimiento independentista americano. Durante el Trienio Liberal, la división entre moderados y exaltados abrió las puertas al restablecimiento del absolutismo, con la ayuda de los Cien Mil Hijos de San Luis. Fernando se fue inclinando hacia los do- ceañistas templados y los reformadores afrancesados vueltos del exilio, dicto leyes modernas como el Codigo de Comercio de $1828 \mathrm{y}$, al refrendar la abolición de la Ley Sálica y designar heredera a su hija Isabel, cerró el paso a su hermano Carlos, de convicciones absolutistas.

El reinado de Isabel II se inició en 1833 bajo la regencia de María Cristina, con una epoca de predominio de los liberales más exaltados, a pesar de la existencia de notables pensadores a los que Díez del Corral ha aplicado el nombre de sus congéneres franceses, los liberales doctrinarios.

Esos gobiernos liberales progresistas hubieron de enfrentarse con los carlistas en la primera guerra de ese nombre. No sería justo afirmar que la causa de la libertad se encontraba toda en el campo cristino o isabelino, pues los carlistas no sólo luchaban contra el progreso y la irreligión, sino también a favor de los fueros y el auto-gobierno: los liberales a la francesa a menudo caen en el centralismo y la uniformidad cuando defienden un Estado que garantice la igualdad ante la ley. Restaurada la paz por el general Espartero, gran prohombre de los exaltados, entonces ya "progresistas", se inicia sin embargo en 1844 la década moderada, bajo el mando del general Narváez. Luego, desde el 54 hasta la Constitución de 1876 puede hablarse de una larga aunque agitada hegemonía de los progresistas: dos años de progresismo sin paliativos de 1854 a 1856 ; doce años de influencia predominante de la Unión Liberal dirigida por el General O'Donnell; profundas reformas liberales tras la "Gloriosa", la revolución de 1868 , que desplaza a Isabel II del trono; confusos cambios de régimen, de entre los que hay que destacar el Gobierno Provisional bajo el general Serrano, el corto reinado de Amadeo I, 
la cortísima I República de 1873 con sus tendencias federalistas, año ese último en que volvió a encenderse la guerra carlista.

Cánovas, antiguo animador de la Unión Liberal, propició la vuelta al trono del hijo de Isabel II, el joven rey Alfonso XII: El liberalismo hegemónico durante esa epoca de restauración se dividió en dos grandes formaciones: el partido aliberal-conservador" de Cánovas, y el "fusionista", luego "partido liberal" de Sagasta. Gracias al llamado Pacto de El Pardo pudieron turnarse estas dos formaciones en el poder. A la muerte de Sagasta se impuso en el partido la figura de Canalejas, antes de caer bajo el arma de un magnicida. Fue un liberal más intervencionista y socializante que lo tradicional: «La pasividad del Estado - decía-, cuando los elementos sociales actúan con una desproporción de influencias y medios tan enorme como la que se advierte en España, equivale a consentir en una absorción que, a título de libertad, hará tabla rasa de todas nuestras libertades». Sucumbía así Canalejas ante la discutible idea de que puede haber un Estado intervencionista que sea independiente de los poderosos.

Para entonces hacía tiempo que se encontraba en el trono Alfonso XIII, hijo póstumo del anterior, y que se había terminado la regencia de su madre la reina viuda Maria Cristina. La pérdida de Cuba y Filipinas en 1898 y la mayoria de edad del joven rey en 1902 marcan el príncipio de una nueva épo$\mathrm{ca}$, en la que el liberalismo político abandona insensiblemente su identificación con el laissez-faire.

El liberalismo económico había ido aumentando su influencia a lo largo del siglo XIX hasta llegar a su culmen precisamente al comenzar Fernando VII; las desamortizaciones eclesiástica y civil con Mendizábal y Madoz en
1835 y 1855 respectivamente; la consm trucción del ferrocarril a partir de 1848; la Ley de bancos de emisión de 1856 y la de sociedades anónimas de 1869; y sobre todo la famosa Base quinta del arancel de 1869 ideado por Figuerola, con que se inició una época de progresiva liberalización del comercio exterior, marcan una época que puede decirse acaba con la notoria declaración de Canovas en su folleto $D e$ como he venido a ser doctrinalmente proteccionista (1890) y con el arancel de 1906. A partir de entonces y hasta la liberalización de 1859 prevalece de nuevo la tendencia proteccionista tradicional en la politica económica española.

El liberalismo social también se reforzo y extendio a lo largo del siglo XIX. La abolición definitiva del Santo Oficio en 1834; el brillante florecimiento de la enseñanza privada con la creación en 1876 de la Institución Libre de Enseñanza, por Francisco Giner de los Ríos y un grupo de catedráticos y profesores de Universidad e Instituto, algunos de ellos de convicciones krausistas; la abolición de la esclavitud en las posesiones españolas en América de 1868 a 1880; la extensión del sufragio, hasta la aprobación de la ley de sufragio universal masculino en 1890; $y$ la consagracion de las instituciones legales burguesas, con la promulgación de diversos Códigos y Leyes, el más destacado de los cuales fue el Civil en 1889: crearon el cuerpo de instituciones de la sociedad más libre hasta entonces conocida en España. Las plenas libertades religiosas, que los catolicos interpretaban como anti-clericales, hubieron de esperar hasta el ministerio de Canalejas de 1911 y 1912 para comenzar a extenderse.

Por un inesperado efecto de la paulatina extensión del ejercicio del sufragio, así como de las ideas socialistas, 
que venian propagándose en Europa desde al menos 1830, los liberales rompieron la coherencia de su credo basado en el individualismo, la igualdad ante la ley, el respeto de la propiedad, y el librecambio. De 1906 a 1910 llegaron al poder en diversos paises de Europa gobiemos liberales que aplicaron una concepción del liberalismo mucho más americana que europea. Lo mismo ocurrió en España.

El «regeneracionismo» como corriente de opinión común a todos los partidos; el Instituto de Reformas Sociales como centro de estudios en busca de soluciones de la llamada "cuestión socialn; las leyes laborales, de pensiones, y otras normas intervencionistas promulgadas principalmente por los gobiernos que presidieran el lider conservador Dato y el liberal Canalejas: señalaron el inicio de una larga época socializante. Si a estos signos unimos en lo político la crisis de los partidos dinásticos, se entiende que por cuanto se refiere a España reservemos la denominación de ssiglo liberal* para el siglo xIX. A pesar del florecimiento en el $\mathrm{xx}$ de señeras figuras liberales, cuales fueron Ortega, Marañon, Azaña, o Madariaga, parece más adecuado reservar para esta centuria el nombre de «siglo del socialismon, o quizá por otras razones «siglo del despotismo». Solo con la disolución repentina del socialismo real, anunciada por grandes pensadores europeos como Von Mises, Von Hayek, lord Robbins, o Raymond Aron, parecen haber cambiado de nuevo las tornas y haberse reiniciado la larga marcha hacia una libertad individual cada vez más profunda.

Sólo a finales del siglo $\mathrm{xx}$ se han impuesto, pues, claramente de nucvo las ideas liberales, por la atracción que el progreso de las democracias limitadas y capitalistas del Occidente ha ejercido sobre el mundo entero.

\section{La etica del capitalismo}

La inestabilidad de los elementos que componen la sociedad democrática liberal, la confusión de las ideas de quienes la interpretan, nos hacia esperar que la peripecia histórica iba a ser movida. Así lo ha mostrado el desarrollo del liberalismo a través de los tiempos, desde 1688 , fecha de la «Glorious Revolution», hasta 1989, el derrumbamiento de las dictaduras comunistas en Europa. El futuro, me atrevo a predecir, habrá de ser igualmente movido.

Si volvemos a las tres cuestiones planteadas al principio de este ensayo, en realidad no me he enfrentado más que con la primera de ellas: si están equivocados quienes postulan una inevitable y definitiva victoria del capitalismo liberal. En todo lo que he escrito hasta aqui se nota mi deseo de que nuestras sociedades vayan perfeccionándose en la aplicación del ideario liberal-democrático. Pero no estoy seguro, ni mucho menos. de que pueda darse por descontada la victoria. Dos veces en este siglo estuvieron las libertades en grave peligro en el Mundo (no digamos en España). Torres más altas cayeron.

Me queda examinar, siquiera brevemente, los argumentos de quienes rechazan la democracia capitalista en nombre de una ética humanista, o la temen por su carácter disolvente de la sociedad tradicional.

Si denominamos uética del capitalismon las reglas de conducta social que necesita la sociedad mercantil para sobrevivir, y amoral del amor propio" las reglas de conducta personal características de las sociedades libres, entonces resulta fácil expresar sucintamente una contradicción que, según muchos pensadores, anida en el corazón del sistema capitalista: la contradicción entre la ética de la sociedad libre y la moral del homo oeconomicus. 
Es casi un lugar común la afirmación de que el sistema capitalista corre peligro de extinción, porque el tipo de moral "egoista" que fomenta en los individuos zapa la observancia de las reglas que lo hicieron nacer $y$ triunfar. El sistema de la propiedad privada y la libertad de contratos, si bien es altamente eficaz en la creación de riqueza, sin embargo se dice que fomenta actitudes personales que lo ponen en peligro. Así por ejemplo, ocurre que, si bien la libertad de comercio es esencial para el progreso capitalista, los mismos empresarios, empujados por su afán de lucro, reclaman constantemente de los poderes públicos medidas proteccionistas. Esa corrupción alcanza a veces a los magistrados de la república, que no cumplen su función como legisladores o como jueces de mantener un marco imparcial para la práctica deportiva del juego económico. O también, el deseo de enriquecerse, lucir y consumir, que es el motor de la acción individual en un sistema mercantil, lleva a muchos a caer en la envidia y a exigir redistribuciones políticas de la riqueza que bloquean el motor del crecimiento.

Mi tesis es contraria a esta visión pesimista de la usociedad de la libertad natural", como la denominaba Adam Smith, respecto de su efecto sobre la moral individual. Me alejo tanto de los cínicos como de los rigoristas, pues ambos ponen al capitalismo en la picota por basarse en el egoísmo, la avaricia, la prepotencia, el consumo desenfrenado, y la ostentacion innecesaria. Todos estos vicios connaturales del ser humano aparecen en la sociedad libre más a las claras que en las pacatas sociedades cerradas de la Edad de Oro, "dichosa", como decía Don Quijote, "porque entonces los que en ella vivían ignoraban estas dos palabras de tuyo y món. Pero esos vicios no son la base y origen de la moral capitalista y aquella edad de oro podía ser dichosa como sin duda es la vida en el seno materno, pero no verdaderamente consciente.

Una cosa es egoísmo y otra cosa amor propio. El egoismo es una degeneración del amor propio, que es la verdadera moral de "la sociedad de la libertad natural", como la denominaba Adam Smith. La primera obligación del ser humano es preservarse a sí mismo y su familia. Como dijo Espinosa un siglo antes que Smith: «cuando cada hombre busca con más ahínco lo que le es útil, los hombres son más útiles los unos para los otros».

\section{El pequeño escocés que todos llevamos dentro}

Adam Smith, frente al rigorismo de un San Agustín y al cinismo de un Mandeville, insiste en que la virtud concebida como negación de uno mismo y de la naturaleza humana es una perversión de la verdadera doctrina, ya quc no existe oposición fundamental entre las exigencias de la moralidad y el bienestar y la plenitud de este mundo. La Teoria de los sentimientos morales es un intento de probar que las normas de la justicia y de la moral no son contrarias a nuestras inclinaciones interesadas, sino que cooperan a que el progreso, a que ese adeseo de mejorar nuestra propia condición» de que habla Smith, tenga lugar en el contexto de un orden armónico.

Para Adam Smith la socicdad puede funcionar tolerablemente bien incluso cuando esté ausente de ella la benevolencia y los individuos persigan únicamente el propio interés -mientras haya justicia: "la sociedad puede mantenerse por medio de un intercambio mercenario de buenos oficios según una valoración previamente establecidas; eso es la justicia para Smith: en 
recibiendo cada uno lo suyo, los hombres colaborarán con los demás para poder enriquecerse y mejorar así su condición. La benevolencia o beneficencia «es el ornamento que embellece, no los cimientos que soportan el edificio [...] La Justicia, por el contrario, es el pilar fundamental que mantiene en pie todo el edificio".

La sociedad, pues, habrá de estar organizada para dar escrupulosamente a cada uno lo suyo. Cuando falla la justicia, cuando reina la violencia, la coacción, el engaño, la corrupción, la sociedad comienza a disolverse y la riqueza se esfuma. La justicia conmutativa, como la habria llamado Tomás de Aquino, es la virtud social por excelencia.

Mas para Smith, esta sociedad mercantil y respetuosa de lo que es de cada uno, también fomenta espontaneamente determinadas virtudes individuales, precisamente esas virtudes que los moralistas han visto como los fundamentos del capitalismo. "A pesar del desorden que parece reinar en las cosas de este mundo, incluso aquí toda virtud recibe a la larga y naturalmente su recompensa, la recompensa más idónea para estimularla y alentarla [...] ¿Cuál es la recompensa más adecuada para estimular la laboriosidad, la prudencia, y la circunspeccion? El éxito en todo tipo de negocios."

Las minimas virtudes capitalistas no son admirables para muchas almas generosas. Pero, añade Smith, wen la carera por la riqueza, los honores, y los ascensos, [el individuo] puede correr tan deprisa como le sea posible y tensar cada uno de sus nervios y músculos para dejar atrás a sus competidores. Pero si empuja o tira por tierra a alguno de ellos, se termina la indulgencia del espectador. Eso es violar el reglamento, no jugar limpio, y eso no puede admitirses,
Esta visión deportiva de la vida y la sociedad es algo más y mejor que la de un tendero escocés, es la de un gentleman, respetuoso del fair play por encima de todas las cosas.

\section{El camino hacia una interpretación agnóstica de la etica del mercado}

David Hume, como correspondía a un filósofo escéptico en la teoría del conocimiento y experimental en cuestiones de ética social, vefa las cosas de manera un poco más distante. Mientras Adam Smith se ocupó sobre todo de los origenes psicológicos y sociales de la moral individual, David Hume estudió directamente el origen y contenido de la ética de una sociedad libre. Para el, la sociedad mercantil era una sociedad sín objetivos propios y con un número corto de reglas éticas esenciales.

En Hume encontramos la idea de una ética social limitada a tres reglas fundamentales, dentro de la cual la libertad, y por tanto las morales individuales privadas, podrian florecer; y la idea de la lenta, insensible y casi darwiniana evolución de las normas $\mathrm{c}$ instituciones éticas a lo largo de siglos de ensayo y error.

Para Hume «las reglas de la moral no son conclusiones de nuestra razón". Son kartefactos", ni ordenados por la divinidad, ni parte de la naturaleza humana general, ni reveladas por la razón pura: son el resultado de una evolución o selección social no planeada por nadie, y cuyos resultados se han visto sometidos al contraste de largos siglos de práctica.

Dado que los individuos se preocupan sobre todo de sí mismos y de sus projimos más cercanos, y que hay escasez de recursos, es indispensable un sistema de justicia. Mas la tal justicia no comprende todas las reglas de la moral individual, tal como luego las 
derivaria Adam Smith del sentimiento de la "simpatfa» y de la aparición del "espectador imparcial». Sólo comprende unas pocas reglas éticas o sistémicas fundamentales, a saber:

- "la estabilidad de la posesión»;

- «su transferencia por consentimienton; y

- wel cumplimiento de las promesas".

Nos encontramos, pues, con dos resultados sorprendentes al criticar la "paradoja del capitalismo". Uno es que la base moral del capitalismo no es el egoismo, el vicio y la corrupción, como dicen tantos amigos de la sociedad cerrada y tribal. El peligro no viene del efecto sobre la sociedad de la corrupción de las costumbres morales.

Otro es que, además de contribuir le doux commerce, en expresión de Montesquieu, a la difusion de las costumbres civilizadas, nacidas del amor propio y la «simpatía», da lugar a que aparezca una meta-moral, una ética, un conjunto de reglas sistémicas que no son en sí ni morales ni inmorales, sino que han servido a lo largo de los años para arropar el crecimiento de la riqueza en un ambiente de seguridad. La ética del sistema capitalista está constituida por muy pocas reglas de justicia formal, no necesariamente acordes con los sentimientos morales prevalentes en la mayoría de una sociedad determinada.

Es decir, que es cierto que puede haber un conflicto entre los sentimientos morales de gran parte de la población de una sociedad capitalista, y las reglas éticas (o de la justicia) de respeto de la propiedad privada, la libertad de contratos, de respeto de los precios libremente formados, y del cumplimiento de los contratos, por el carácter abstracto y agnóstico de éstas.

Pero el comentario sobre las dificultades del hombre moderno de aceptar como justas valoraciones que no son ni naturales ni racionales, sino que son nacidas de la evolución social, debe ser objeto de otro trabajo.

\title{
El «éxito» del neoliberalismo
}

\author{
ANTONIO GARCIA SANTESMASES \\ U.N.E.D.
}

Creo que la forma más acertada de estudiar las distintas caras del neoliberalismo es plantear la relación entre democracia y capitalismo en este fin de siglo. La relación entre democracia y capitalismo ha pasado por distintas etapas, pero conviene recordar que a principios de siglo la tesis que prevaleća en el campo liberal y en el mundo socialista era la de la incompatibilidad entre democracia y capitalismo. Para los liberales el temor fundamental se cifraba en los peligros que a su juicio entrañaría la extensión del sufragio universal. Para los socialistas, por el contrario, la gran esperanza se cifraba en la extensión del sufragio, ya que si votaban todos, siendo los más los asalariados, éstos podrían articular una coalición invencible frente a los menos 